\title{
'I start my day by thinking about what we're going to have for dinner' - A qualitative study on approaches to food-related activities among elderly men with somatic diseases
}

\author{
Kerstin Kullberg $^{\mathrm{a}}$, Anita Björklund ${ }^{\mathrm{b}}$, Birgitta Sidenvall ${ }^{\mathrm{c}}$, Anna Cristina Åberg ${ }^{\mathrm{a}, \mathrm{d}}$
}

\author{
${ }^{a}$ Department of Public Health and Caring Sciences, Uppsala University. \\ ${ }^{b}$ Department of Rehabilitation, School of Health Sciences. \\ ${ }^{c}$ Department of Nursing Science, School of Health Sciences. \\ ${ }^{\mathrm{d}}$ The Swedish School of Sport and Health Sciences, Stockholm
}

\begin{abstract}
The aim of the present study was to address the question of how older men with somatic diseases living in ordinary housing approach the question of food-related activities. Further, any food-related activity adaptations consequent to effects of diseases and of altered life circumstances were explored. Interviews were conducted with a purposeful sample of 18 co-living and single-living men, $64-84$ years old. They were diagnosed with Parkinsons' disease, rheumatoid arthritis, or stroke. In the analysis a thematic framework was used. The findings revealed three food-related approaches, namely 'Cooking as a pleasure', describing joy in cooking; 'Cooking as a need', indicating no habit or skills in cooking; and 'Food is served', that is being served meals by a partner. It was found that gender-related roles in particular, but also changed life circumstances, activity limitations, personal interests, and a wish to maintain continuity and independence, affected the men's approaches to these activities. This knowledge may be useful in attempts to facilitate and support food-related activities among elderly men with diseases. Health-care efforts in promoting food-related activities should preferably be individualised in respect to older men's approach to these activities.
\end{abstract}

Keywords: activities of daily living, adaptation, arthritis rheumatoid, cookery, gender role, men, limitations of activity, older people, Parkinson disease, stroke 


\section{Introduction}

Elderly European men with different diseases living in their own homes have been found from a nutritional perspective, to be a vulnerable group (1). Previous research has indicated that Parkinson's disease, rheumatoid arthritis (RA) and stroke are three examples of diseases that may influence the capacity to perform food-related activities (FRA) such as grocery shopping and cooking $(2,3,4)$. It has also been suggested that older single-living men with such diseases should be paid particular attention with regard to possible foodrelated difficulties (5). Nevertheless, only few studies have focused on FRA from the perspective of elderly men. This study was therefore directed at improving the understanding of the approaches and attitudes to such activities among older men with diseases.

Food-related activities and eating can be regarded as central components in the activities of daily living, as we eat several times a day and as over the years these activities give structure and continuity to our everyday lives. With reference to the continuity theory, older persons show consistency over time in their patterns of thinking and in their activity profiles (5). Nevertheless, eating preferences as well as performance in FRA change over time, indicating that continuity and change may exist simultaneously in the lives of elderly. Hence, ageing is seen as a process in which the individual grows, adapts and changes (6). From this it follows that adaptation is one of the central concepts in the continuity theory of ageing.

In Sweden, there has been a trend in recent decades, also for very old people, to remain living in ordinary housing (7). If they need support with FRA, older Swedish people have the rights according to the Swedish social service legislation (8), to receive such help from the municipality. However, about $90 \%$ of the older people in Sweden, aged $\geq 65$ years, who remain living in ordinary housing, manage FRA on their own, without any formal support (National Swedish Board of Health and Welfare, 2005).

Everyday cooking has traditionally been described as the women's sphere $(9,10,11)$, and according to earlier research older women have greater cooking skills than older men in the same age group $(12,13)$. However, the perceived need for help with cooking among older Swedish men 65 years and older has significantly decreased since the end of the 1990s (14). This may indicate that today older Swedish men are more involved in cooking, and they probably also have greater cooking skills than men of the same age group had fifteen years ago. Additionally there may be a desire among older men to manage FRA without help, as independence in daily activities is highly valued in our western culture (15).

The aim of the present study was to address the question of how older men with somatic diseases living in ordinary housing approach the question of FRA. Further, any FRA adaptations consequent to effects of diseases and of altered life circumstances were explored.

\section{Method}

\section{Participants}

To fulfil the aim of the present study, a purposeful sample of 18 men was chosen from participants included in the more extensive project 'Older men and Food' (OMF) (5). These were identified from hospital registers and were $64-84$ years of age and all living in a county in central Sweden. Exclusion criteria were: diagnosis of dementia, acute illness or severe aphasia, not living in ordinary housing, and inability to communicate in Swedish. The process of inclusion in the entire project has been described in more detail elsewhere 
(5). In the present study a sample of participants was recruited on the basis of the criteria: one of the three diseases Parkinson's disease, RA or stroke, civil status (with the aim of having an equal number of single-living and co-living participants), and location of residence (urban vs. rural). The entire project was approved by the Committee of Research Ethics at the Medical Faculty, Uppsala University.

Demographics of the participants and an overview of the use of mobility devices, driving a car, and home help services are presented in Table 1. All co-living participants were living together with a female partner in their own age group.

Table1. Demographics of the participating men and an overview of the use of mobility devices and received help with food-related activities (FRA) from home help services.

\begin{tabular}{|c|c|c|c|}
\hline & $\begin{array}{l}\text { Co-living } \\
(n=9)\end{array}$ & $\begin{array}{l}\text { Single-living } \\
(n=9)\end{array}$ & $\begin{array}{l}\text { All } \\
(n=18)\end{array}$ \\
\hline Age, (mean yrs) & 71.1 & 74.1 & 73.7 \\
\hline
\end{tabular}

\section{Disease}

$\begin{array}{llll}\text { Parkinson's disease } & 3 & 3 & 6 \\ \text { Rheumatoid arthritis } & 3 & 3 & 6 \\ \text { Stroke } & 3 & 3 & 6\end{array}$

Location of residence

$\begin{array}{llll}\text { Urban } & 7 & 6 & 13 \\ \text { Rural } & 2 & 3 & 5 \\ \text { Mobility device } & 4 & 3 & 7 \\ \text { Driving a car } & 7 & 6 & 13 \\ \text { Home help services } & & & \\ \text { Meals-on-wheels } & 0 & 1 & 1 \\ \text { Grocery shopping } & 0 & 2 & 2\end{array}$

\section{Data collection and analysis}

Qualitative interviews were conducted by the first author, to gain a deeper understanding of the participants' approaches to FRA. One of the interviews was conducted by a late coresearcher. The interview guide used included questions about whether, when and how the men participated in and managed food preparation and grocery shopping, including planning for the shopping and transportation to and from the store. Further, the participants were asked about any change in performances and any FRA adaptations consequent to effects of the disease and/or to altered life circumstances. In addition, the interviews focused on the participant's perceived experiences of FRA. As the interviews were part of the data collection for the entire OMF project, the participants were visited in their home on two occasions, usually with an interval of two weeks. The interview was conducted at 
the first home visit. Afterwards, shortly after the visit, the recorded audiotape was listened to, which gave an opportunity for an initial overview of the content and also disclosed any need for further details. At the second home visit complementary questions were asked and statements made at the first interview were confirmed. The interview, which commonly lasted for 45 to 120 minutes, was performed as a dialogue around the themes in the interview guide. All interviews, including complementary questions in eight participants, were audiotape recorded and transcribed verbatim. The transcribed material was analysed in line with a 'thematic framework' approach $(16,17)$. In order to become familiar with the data set, the interviews were listened to and carefully read several times. In the next step, the interviews from each of the participants were read, and preliminary themes related to the aim of the study were identified and noted in the transcripts. Thereafter, in a cumulative order, similarities and differences within and between themes among all participants were identified and noted. In this process of analytic induction (18), analyses and the interpretation process repeatedly moved backwards and forwards between the raw data and the preliminary themes, and thus the final themes describing the participants' approaches to FRA were refined and distilled. Finally, the whole data set was checked, with the purpose of detecting explanatory factors and patterns (17) for maintenance of or changes in FRA approaches over time.

\section{Results}

The results revealed three main themes representing the FRA approaches, namely: Cooking as a pleasure, Cooking as a need, and Food is served, as presented below. Additionally, the interviews indicated that over time these approaches to FRA were dependent on the individual's gender-related role, skills and habits in performing these activities as well as on civil status and activity limitations. Together with some specific adaptation strategies connected with FRA, these processes are described in the last part of the results section, under the heading Continuity and adaptation of approaches to food-related activities.

In this study continuity referred to the individual's ability to perform FRA, and also factors over time such as preferences, skills and self-perception (19). In line with White (20), adaptation is defined as a master concept including defence mechanisms, mastery and coping. Defence mechanisms concern adaptation in situations of current danger and anxiety, mastery has been connected with defeat and victory, and coping is an adaptive strategy resorted to under relatively problematic conditions. Adaptation in the present study refers to the means by which the participants coped with altered life circumstances and activity limitations due to disease.

\section{Cooking as a pleasure}

Participants with the approach Cooking as a pleasure described themselves as having both an interest and skills in FRA. They cooked almost entirely from raw fresh ingredients, and for them cooking was a joy. A man with RA said that he often started his day by thinking about what he would have for dinner:

....and sometimes I start my day by thinking about what we're going to have for dinner today. This is like a little festival, yes it's fun... and then something might be missing, and I go to buy it, onions, or whatever is needed, cream...so it's planned in my head the whole day. (Co-living, 67 yrs, RA)

The participants adopting this approach often said that they had taken up cooking a long time ago, and at the time of the interview some participants cooked almost all hot meals in 
the family. Some men said it had been difficult when they first started to cook, but with practice their confidence and competence had grown. Sometimes the amount of time spent on cooking had increased in connection with retirement, a divorce or a partner's serious illness.

Some participants mentioned receiving inspiration from recipe books, the Internet and television. A man described how he used the recipe book as a motivation when he thought he needed to renew his cooking ability. Other, who had been cooking continuously, stressed the importance of sharing the responsibility for FRA with their partner. Both the woman and the man had usually been working full-time in these families. Other participants who regularly performed FRA described a more defined division of labour in the kitchen, like usually being the one who made pancakes or fried fish. Activity limitations from disease were not always a hindrance in developing culinary skills. On the contrary, such limitations could be part of the motivation to take on cooking as a way of sharing the responsibility for the household with their partner:

... I could hardly boil an egg... so, when I became ill I made a demand on myself to help out...but it wasn't that easy as I have very poor fine motor skills in my fingers, so I don't dare do the dishes we have a dishwasher, but it doesn't work very well either...well, I do what I can, which includes cooking. (Co-living, 67 yrs, RA)

Most of the participants who found cooking a pleasure also said that they took an active part in grocery shopping, including planning for the shopping. It could be assumed that among participants with cooking as a pleasure approach, taking part in FRA contributed to overall well-being.

\section{Cooking as a need}

Participants with the approach Cooking as a need, had no skills or habits in FRA, and they described performing these activities first of all as a need. With the aim of minimising and simplifying the FRA performances, these participants looked for cooking alternatives. One way to simplify cooking was the use of convenience food, and to buy ready-made meals, which besides being fairly cheap were fast and easy to heat up in the microwave oven:

...it is easy (ready-made meals), it is fast...almost close to something you can call cheap...to eat in that way means you get rid of a lot of trouble...I don't like spending a long time in the kitchen or handling food, so if it possible to prepare it in a short time I think that is the best for me... (Single-living, 64 yrs, Parkinsons' disease)

For those who had become widowers and suddenly found themselves responsible for managing FRA on their own, inexperience and lack of competence could be a problem. Afraid of risking failure, a widower with RA said that he avoided cooking with fresh raw ingredients:

Well, you can't do that either...because if you take just any old thing it might be just gunk, something inedible. (Single-living, 81 yrs, RA)

As a complement to their own simplified cooking and to ready-made meals, some participants said that they now and then went to a lunch restaurant.

Participants with this approach said that they did not always plan a great deal before going to the grocery store, but sometimes just had some staple foods on their list. It happened that they just browsed through the store looking at the shelves and freezers to find something appealing: 
Quite often I don't know what to eat, I just go round the store looking at what there is, and then I buy something for a particular meal, I come home with a pie or a readymade meal or something that you just have to put in the oven. (Single-living, $64 \mathrm{yrs}$, Parkinson's disease)

To go shopping at a supermarket was not always seen as an efficient alternative for a single-living person. One man explained that he gave up going to the supermarket when he became a widower, as the groceries there were sold in large family packs, too large for a one-person household. Some men in this group appeared to have no interest in FRA and expressed a total lack of concern. They were more or less only 'cooking for survival'.

Food is served

Participants with the approach Food is served were all co-living and thus provided with meals by a female partner, and took no or only a minor part in FRA, particularly in cooking:

Cooking, I don't do that... and I don't need to do it either. (Co-living, 80 yrs, stroke)

Men in this group commonly regarded cooking as being the 'women's sphere' to which they had never been invited. Hence, participants with the approach Food is served usually lacked both skills and habits in cooking. Despite being served meals co-living participants often said that they helped with some household work like laying the table, taking food out of or putting it back into the refrigerator, and washing up. Although they had only a slight or no interest in cooking, participants with the approach Food is served usually said that they went grocery shopping with their partner, but it was always the woman who wrote the shopping list and decided what to buy. All that the men did in the store was usually to help the woman with the shopping trolley:

My wife goes shopping and I push the shopping trolley...when you have a full shopping trolley it is difficult to manage on your own, when you come to unload it at the cash desk. (Co-living, 74 yrs, Parkinsons' diseases)

However, because of activity limitations some participants with the approach Food is served were not as involved and active in FRA as they wished and/or used to be. A coliving man with Parkinson's disease said that he had had a dream about taking up cooking more regularly after retirement. Although he was not able to do any cooking, he kept things under control and discussed with his partner about how to make the food tastier:

I've tried to influence my partner, as the salad in itself doesn't taste of anything. It's what you add to it; it's the spice mixtures. Preferably sheep's cheese with different types of oil and cream (Co-living, 68 yrs, Parkinsons' diseases)

It appeared that for most of the participants with the approach Food is served, cooking was a 'non-activity' for which they had never been responsible. On the other hand, the current non-cooking situation was a disappointment or even a frustration for those who had previously taken an active part in FRA.

\section{Continuity and adaptation of approaches to food-related activities}

A majority of the participants emphasised continuity of FRA as being an important issue. For addressing the aim to maintain continuity in FRA, firstly, with the purpose of adjusting to activity limitations due to disease, specific adaptive strategies were used, and secondly, to adapt to changed life circumstances, such as an altered civil status and/or severe activity 
limitations, the participants changed their approach to FRA. Sometimes these two ways of adjustments were combined, so that both were used together, commonly in an attempt to maintain independence. Single-living participants, in particular, expressed a wish for independence, which was described as a strong driving force for adaptation and also for an ability to maintain as much continuity as possible in these activities. For this latter purpose three specific adaptive strategies were used, namely Physical reorganisation, Interaction with others, and Passively attended.

Physical reorganisation included adaptations such as optimising, simplifying and modifying performances, and the use of assistive devices. In particular single-living participants with no skills or habits in cooking simplified the cooking procedure by the use of convenient foods including ready-made meals. Some single-living participants with activity limitations said that they preferred this somewhat simplified cooking to receiving meals-on-wheels. A single-living man, who was severely disabled from a stroke, said that he had his freezer filled with a set of dishes cooked by a relative which he took out, heated up and supplemented with some fresh ingredients. Since he had both skills and habits in FRA this modified cooking was a way for him to maintain continuity:

I take it out in the evening (from the freezer), and then put it in the fridge so that it will thaw...I prefer to heat it up in a saucepan, because then I am able to put in some supplements... for example now when I have bought some vegetables I put them in, all together... as I can't dish it up onto more than one plate... it works quite well...you know these fingers don't really want to...they don't move at all in the way I want them to do. (Single-living man 84 yrs, stroke, Cooking as a pleasure)

Physical reorganisation in the sense of using assistive devices, for example taking a walker to the grocery shop, was one way to compensate for not being able to drive. Otherwise, an ability to drive facilitated grocery shopping and helped the participants to stay independent in this activity. Among driving participants, the shopping trolley was mentioned as a good mobility device, to compensate for walking difficulties and impaired balance. Instead of taking the walker to the store, one man took a shopping trolley on the parking lot. He explained:

When I get to a store, a larger one, then I always takes a shopping trolley, even if I'm not going to buy anything. The trolley is super...you can see people walking with their arms on them, hanging on to them. (Single-living, $81 \mathrm{yrs}$, RA, Cooking as a need)

Interaction with others was an adaptive strategy that was identified among participants with activity limitations and with a wish to continue performing FRA. In contrast to single-living men, co-living participants had the opportunity to interact with their partner regarding FRA. A co-living man with RA used to call his partner when he needed help with cooking:

...then I call her - Could you please help me take this out of the oven...putting things in the oven works quite well, but taking them out is difficult, because you need potholders and things, it's impossible, I must have help...but, she likes to do it. There's no problem because she's my best assistive device. (Co-living, 67 yrs, RA, Cooking as a pleasure)

Even when severely disabled, some participants expressed a wish to continue performing at least some FRA independently. A co-living man disabled from RA said that he did not want 
to adapt completely to his partner's preferences in food and eating times. Being able to heat up ready-made meals was one way to remain independent, and also to make things easier for his partner:

We usually arrange it so that I can reach (food to be heated up), then there's the micro, today there are very good ready-made meals...I can manage, if someone has taken it out earlier, and put it in the fridge... (Co-living, 68 yrs, RA, Food is served)

Even though they received help from the home help services, some single-living participants with activity limitations described how they maintained continuity and independence, and thus their approach to FRA by just accepting minimal help. A singleliving man who had had a stroke, said that he did not trust the home-helper's knowledge about buying fresh vegetables, fruit and meat. For this reason he went to the store himself by taxi once a week to buy these items. Another single-living man, who was helped with grocery shopping described difficulties in maintaining a varied diet. He felt that being kept from going to the grocery store, and not being able to see the supply of products himself, negatively affected his eating habits:

It was more varied, because then I went to the store myself...bought some meat or perhaps some Baltic herring...more varied fruit,...It's not the same as when you go to the store yourself; then you can have a look at what there is to buy. (Single-living, 77 yrs, stroke, Cooking as a need)

Passively attended was another adaptive strategy to maintain continuity in FRA. This described by a participant who was severely disabled from RA. At the time of the interview he was unable to carry out any FRA, but he said that previously he had had great interest in performing these activities, especially cooking from game meat. Although not able to do any shopping, he sometimes enjoyed accompanying his partner to the grocery store, just to sit down and savour the atmosphere:

...you are faced with facts... anyhow you get two directions to choose between; you can sit down and mope or die, or you can forget about moping and start living. I chose the latter alternative... I pick out the small dainties I can get from it...(later in the interview) Sometimes it's fun to go into a store, just to smell the fruits and vegetables... I just sit and rest for a while. (Single-living, 68 yrs, RA, Food is served)

Achievement of continuity and satisfaction with FRA performances depended upon how well the participants managed to adapt to any changes in life circumstances and activity limitations. Those who had been living in a partnership with non-traditional gender roles, implying shared responsibility for FRA, consequently had skills and habits in performing these activities. For them, an altered civil status did not affect their possibility of maintaining continuity, and thus an FRA approach Cooking as a pleasure. Participants with this approach expressed overall satisfaction with their performances in FRA. On the other hand, participants with the approach Food is served who all their adult life had been living in a partnership with traditional gender-related roles, also expressed satisfaction with their current approach and non-participation in FRA. Nevertheless, if and when their life was suddenly changed by widowhood, it was no longer possible for them to maintain continuity in FRA and meal habits. These participants usually felt forced to adapt by changing their approach to Cooking as a need, and expressed no FRA-related satisfaction. 


\section{Discussion}

The present findings provide new knowledge by identifying three approaches to FRA i.e. Cooking as a pleasure, Cooking as a need, and Food is served. It also indicates that older men, even if disabled, strive for continuity in FRA. Factors such as gender-related roles, civil status, personal interests, and skills and habits in performing FRA were significant for maintenance of continuity in older men's approaches to these activities. With the purpose of maintaining continuity and independence in FRA, the three main adaptive strategies Physical reorganisation, Interactions with others, and Passively attended were used.

These findings suggest that traditional gender-related roles, in the age-group studied here, may be important in that reciprocal interplay in FRA between the older man and his female partner maintains the approaches and activities. Other research has indicated that women still are the primary actors in the FRA, because this may work as a confirmation of the feminine gender identity (21). Moreover, the meaning of cooking among older Swedish women, has been described in terms of giving the meal as a gift to their partner (22). Hence, it could be assumed that in the traditional gender-related role as being a food receiver, it is a long-engrained habit not to interfere too much with the 'women's sphere', but to value the woman in her role as a food provider and the 'chef' of the family.

Further, there were indications in the present study that men who had a partner with only a moderate interest in FRA could be helpful for developing cooking skills. An alternative interpretation, however, may be that some female partners decided to step back from cooking activities in favour of a disabled partner's need to contribute to home management and to be engaged in something creative. Moreover, this appeared to potentially reinforce a feeling of competence among the men, as an obviously more positive alternative to feelings of being a burden on the significant other. Nevertheless, living in a partnership with traditional gender roles in FRA, and thus being provided with meals by a female partner, may pave the way for possible future food-related problems. In the present study, particularly widowed men without the skill to cook were found to have considerable difficulties in managing FRA on their own. Such difficulties have previously been identified (23), in that men who suddenly found themselves alone were commonly considered helpless, lacking the necessary skills to provide themselves with the diet they wanted to eat.

Most of the men in the present study, even those with activity limitations, drove and had access to a car. This enhanced their independence, especially if they lived in a rural area. According to the National Swedish Board of Health and Welfare (14), about $37 \%$ of the women $>80$ years of age had help with grocery shopping from the municipality, compared with only about $24 \%$ of the men of that age. One explanation may be that women in higher age groups are less likely than men in the same age group to drive or have access to a car. This also means that it may be problematic for non-driving older men with mobility limitations to remain independent in their grocery shopping, as fully stocked neighbourhood stores are increasingly being shut down (24).

The present findings showed that particularly single-living older men with only a little or no experience in FRA, simplified these activities. These men commonly used a large amount of convenience food, such as ready-made meals in their cooking, and expressed no interest in developing cooking skills. This is in line with findings in an earlier study including older single-living men, where motivation to cook was found to be an important contributing factor for healthy eating (25). Accordingly, extreme simplification of cooking, which in the present study was observed particularly in the group of singleliving men with no skills or habits in FRA, may be an indicator of nutritional risk. 
Moreover, the included single-living men with activity limitations expressed a strong wish to remain independent in FRA, and hence preferred to accept only minimal help from the municipality. This finding is in line with previous research among older persons, which showed that receiving help from others - particularly in household activities and personally valued activities - is associated with a negative effect on their independence (26).

Consequently, single-living older men may need information and support in choosing nutritious alternatives among the great supply of convenience food and ready-made meals available in the grocery store.

Among older men with the approach Cooking as a pleasure performance in FRA often implied a feeling of well-being. Thus it may be speculated that these activities might contribute to overall life satisfaction in this group of men. Such an interpretation is supported by a Finnish study including middle-aged men, in which it was found that cooking contributed to life satisfaction among those who regularly cooked (27). Further, it has been found that daily activities such as FRA can be regarded as part of an ongoing process of self-expression, which through interaction with the environment maintains continuity of the self and creates satisfaction and meaning in older people's lives $(28,29)$. In particular the ability to maintain familiar activities in one's own home, has been shown to promote a positive self-image, which is associated with a high degree of life satisfaction (30), which may also be valid for FRA.

\section{Methodological considerations}

Several procedures were carried out to guarantee the quality of the data collection and analysis. With the aim of ensuring satisfactory data variability, the participants were distributed among the three diseases, two civil statuses, and rural and urban locations of residence. The interviews were conducted in the participants' home, which strengthens the reliability of the interview results. Further, to ensure depth in the data collection, the interview took the form of a conversation, using open-ended questions, and the participant was given considerable time to express himself. Tapes were checked by one of the coauthors to guarantee the documented quality. To ensure the credibility of the findings, the data analysis process involved ongoing comparisons within and between the interviews (18). Based on the reliability of the research process, as described above and in the results section, the conclusions and practical implications should be transferable to older men with other chronic diseases and to contexts similar to the researched area (31).

\section{Conclusion and practical implications}

By identifying three different approaches to FRA displayed by older men with somatic diseases, the present findings add to the understanding of the grounds for how such activities are valued and managed by this group. In particular gender-related roles, but also any activity limitations and change in life circumstances such as widowhood, affect the approaches of older men to FRA. Driving forces such as personal interests and a wish to remain independent may also influence the approach to these activities. Some men for example, will be pleased to be served meals while others, even if severely disabled, achieve well-being and satisfaction by keeping up performances in FRA as much as possible. This knowledge should be useful in attempts to facilitate and support FRA among older men with diseases. Moreover, health-care efforts in promoting FRA should preferably be individualised in respect to the approach of older men to these activities.

\section{Acknowledgements}

Our special thanks to Kerstin Gustafsson RNT, PhD, who died in June 2006, for participating in data collection. 


\section{Author contribution}

The first author took main responsibility for the data collection and for writing the manuscript. The third author had the main responsibility for the design. All authors have contributed in the data analysis and the interpretation of the results, and also in the writing up process.

\section{Funding}

Funds were provided from the Vardal Foundation for Health Care Sciences and Allergy Research, the Research Programme "Arts in Hospital and Care as Culture", and the County Council in Stockholm, The Swedish Stroke Association, and from the Swedish Association of Persons with Neurological Disabilities.

\section{References}

1. Schroll K, Carbajal A, Decarli B, Martins I, Grunenberger F, Blauw YH, de Groot CPGM. Food patterns of elderly Europeans. Eur J Clin Nutr 1996; 50 Suppl 2: 86100.

2. Lorefält B, Ganowiak W, Wissing U, Granérus A-K, Unosson M. Food habits and intake of nutrients in elderly patients with Parkinson's disease. Gerontology 2006; 52: $160-168$.

3. Pajalic Z, Karlsson S, Westergren A. Functioning and subjective health among stroke survivors after discharge from hospital. J Adv Nurs 2006; 54: 457-466.

4. Westhoff G, Listing J, Zink A. Loss of physical independence in rheumatoid arthritis: interview data from a representative sample of patients in rheumatologic care. Arthritis Care Res 2000; 13: 11-22.

5. Kullberg K, Åberg AC, Björklund A, Ekblad J, Sidenvall B. Daily eating events among co-living and single-living diseased older men. J Nutr Health Aging 2008; 12: 176-182.

6. Atchley RC. Continuity and adaptation in aging. Creating positive experiences. 1999, Johns Hopkins University Press, Baltimore.

7. National Swedish Board of Health and Welfare. Vård och omsorg om äldre. Lägesrapport 2007. (Health care for the elderly. Situation description, year 2007): 2008, Socialstyrelsen, Stockholm.

8. SOL (2001:453) Socialtjänstlagen (Social Services Act). Ministry of Health and Social Affaires. 2009, Mars, Google, http://www.regeringen.se

9. Ekström Pipping M, Fürst L'orange E. The gendered division of cooking. In Eating patterns. A day in the lives of Nordic peoples (Kjaernes U ed.), 2001 National institute for consumer research, Lysaker, Norway, 91-123.

10. Gough B. 'Real men don't diet': An analysis of contemporary newspaper representations of men, food and health. Soc Sci Med 2007; 64: 326-337.

11. Sayer LC. Gender, time and inequality: Trends in women's and men's paid work, unpaid work and free time. Social Force 2005; 84: 285-303.

12. Donkin AJM, Johnson AE, Lilley JM, Morgan K, Neale RJ, Page RM, Silburn RL. Gender and living alone as determinants of fruit and vegetable consumption among the elderly living at home in urban Nottingham. Appetite 1998; 30: 39-51. 
13. Bennett KM, Hughes GM, Smith PT. "I think woman can take it": widowed men's views and experiences of gender differences in bereavement. Ageing Int 2003; 28: 408-424.

14. National Swedish Board of Health and Welfare. Hemtjänsten och de äldres behoven jämförelse över tid. (Home-help service and the need for help among older persons - a comparison over time). 2005 Socialstyrelsen, Stockholm.

15. De Craemer W. (1983). A cross-cultural perspective on personhood. Milbank Mem Fund Q Health Soc 1983; 61: 19-34.

16. Spencer L, Ritchie J, O’Connor W. Analysis: Practices, principles and processes. In Qualitative research practice. A guide for social science students and researchers. (Ritchie J, Lewis J eds.), 2003 Sage Publications LTD, London, 199-218.

17. Ritchie J, Spencer L, O’Connor W. Carrying out qualitative analysis. In Qualitative research practice. A guide for social science students and researchers (Ritchie J, Lewis J eds.), 2003 Sage Publications LTD, London, 219-262.

18. Hammersley M, Atkinson P. Ethnography: Principles in Practice. 2nd edn. 1995 Routledge, London.

19. Atchley RC. A continuity theory of normal aging. Gerontologist 1989; 29: 183190.

20. White RW. Strategies of adaptation an attempt at systematic description. In Coping and adaptation (Coelho GV, Hamburg DA, Adams JE eds.) 1974 Basic books, New York, 47-68.

21. Fürst L'orange, E. Cooing and femininity. Women's Stud Int Forum 1997; 20: 441449.

22. Sidenvall B, Nydahl M, Fjellström C. The meal as a gift - The meaning of cooking among retired women. $J$ Appl Gerontol 2000; 19: 405-423.

23. Sydner YM, Sidenvall B, Fjellström C, Raats M, Lumbers M. Food habits and food work: The life course perspective of senior Europeans. Food, Cult Soc 2007; 10, 368-387.

24. Forsberg H. Institutions, consumer habits and retail change in Sweden. J Retail Consum Serv 1998; 5: 185-193.

25. Hughes G, Bennett KM, Hetherington MM. Old and alone: barriers to healthy eating in older men living on their own. Appetite 2004; 43: 269-276.

26. Gignac MAM, Cott C, Badley EM. Adaptation to chronic illness and disability and its relationship to perceptions of independence and dependence. $J$ Gerontol B Psychol Soc Sci Soc 2000; 55B: 362-373.

27. Roos G, Prättälä R, Koski K. Men, masculinity and food: interviews with Finnish carpenters and engineers. Appetite 2001; 27: 47-56.

28. Åberg AC, Sidenvall B, Hepworth M, O'Reilly K, Lithell H. Continuity of the self in later life: Perceptions of informal caregivers. Qual Health Res 2004; 14: 792-815

29. Åberg AC, Sidenvall B, Hepworth M, O'Reilly K, Lithell H. On loss of activity and independence, adaptation improves life satisfaction in old age - a qualitative study of patients' perceptions. Qual Life Res 2005; 14: 1111-1125.

30. Åberg AC. Care recipients' perceptions of activity-related life space and life satisfaction during and after geriatric rehabilitation. Qual Life Res 2008; 17: 509520.

31. Lewis J, Ritchie J. Generalizing from qualitative research. In Qualitative research practice. A guide for social science students and researchers (Ritchie $\mathrm{J}$, Lewis $\mathrm{J}$ eds.), 2003 Sage Publications LTD, London, 263-286. 